\title{
Accessing singular antecedents in conjoined phrases
}

\author{
JASON E. ALBRECHT \\ Texas Tech University, Lubbock, Texas \\ and \\ CHARLES CLIFTON, JR \\ University of Massachusetts, Amherst, Massachusetts
}

\begin{abstract}
Two experiments examined processing of singular pronouns when the antecedent (e.g., Mary) was a noun phrase (NP) in a conjoined phrase (e.g., Mary and John). Whole-sentence reading times showed an increase in processing time associated with splitting the conjoined phrase to access a single NP antecedent. The increase in processing occurred both when the antecedent was in the subject position and when it was in a nonsubject position. The source of the disruption was further investigated using eyetracking methods. Summing over regions of the text, the magnitude of the processing cost incurred by having to split a conjoined NP was closely comparable when there was and when there was not a gender-appropriate distracting potential antecedent. When there was no such potential antecedent, the increase in processing time occurred immediately in the pronoun region when eye movements were measured. In contrast, when there was a second discourse entity that matched the gender and number of the pronoun (but was not a plausible antecedent for the pronoun), eyetracking measures suggested that the processing difficulty was delayed until additional information was read that forced the antecedent to be one of the conjoined NPs. The results are interpreted in terms of Sanford and Garrod's (1981) scenario-based model of text comprehension.
\end{abstract}

A central issue in language comprehension research concerns how pronouns and other terms with discourse antecedents are understood. Readers faced with such a term must recover an appropriate antecedent for the term. This task is influenced by factors such as contextual presupposition, accessibility of antecedent information, and the referential role of the pronoun (Garrod, 1994; Garrod \& Sanford, 1994; Gordon, Grosz, \& Gilliom, 1990; MarslenWilson, Levy, \& Tyler, 1982; McKoon \& Ratcliff, 1980; O'Brien, Duffy, \& Myers, 1986).

Much of the research investigating terms with discourse antecedents has focused on the processing and understanding of singular pronouns. It has addressed questions about the ease of finding an antecedent for a pronoun when the antecedent is in different positions in the syntactic struc-

The research reported here was conducted as a collaboration between J.E.A. and C.C. while J.E.A. was supported by a National Institute of Mental Health Training Grant (MH 16745) awarded to the Department of Psychology, University of Massachusetts. The research was also supported in part by NIH Grant HD 18708 to the University of Massachusetts. The report of the research was initially written by J.E.A. at Texas Tech University. However, due to his untimely death, the present version was completed by C.C., who must take responsibility for any errors that may have crept into it. Thanks are due Jerome Myers and Lyn Frazier for helpful comments on earlier versions of this paper. Correspondence should be addressed to C. Clifton, Department of Psychology, University of Massachusetts, Amherst, MA 01003 (e-mail: cec@psych. umass.edu).

Note: Jason E. Albrecht passed away unexpectedly in the spring of 1996 Many researchers in the field, including the editor of Memory \& Cognition, continue to mourn the loss of this promising young text and discourse researcher. ture or in the discourse, about the relative availability of different possible antecedents for a pronoun when a choice must be made, and about the roles of various types of information (e.g., causality, morphological marking, and focus) in interpreting pronouns (Caramazza, Grober, Garvey, \& Yates, 1977; Clark \& Sengul, 1979; Ehrlich, 1980; Ehrlich \& Rayner, 1983). Here we examine the reading of a singular pronoun when that pronoun must take one of two conjoined noun phrases (NP) as its antecedent (e.g., John and Mary ... He ... ). We ask what factors are involved in finding a singular antecedent in a conjoined NP. Our ultimate goal is to shed light on questions involving the nature of the conceptual entity that a pronoun takes as antecedent and on the factors that encourage or discourage treating a set of individuals as an entity that can serve as the antecedent of a pronoun.

Research by Sanford and Garrod and their colleagues (e.g., Garrod \& Sanford, 1982; Sanford \& Lockhart, 1990; Sanford, Moar, \& Garrod, 1988; Sanford \& Moxey, 1995; see also Clifton \& Ferreira, 1987) has addressed this last question. In many of their experiments, they have manipulated factors that influence the perceived prominence of discourse entities (e.g., Sanford et al., 1988) and the possible roles that these entities may play (e.g., Sanford \& Lockhart, 1990; Sanford \& Moxey, 1995). For example, Sanford and Lockhart (1990) had participants provide continuations for sentences like the following: ${ }^{1}$

(1) Aileen and Steve ran into the cinema.

(2) Aileen ran into the cinema with Steve. 
Without additional context, the syntactic structure of Sentence 1 encourages participants to map Aileen and Steve into the same role in a discourse event. Although one implication of Sentence 2 is that the entities may participate in the same role, the syntactic structure does not encourage this interpretation. Sanford and Lockhart found that participants were more likely to treat Aileen and Steve as a single entity and use a plural pronoun following Sentence 1 than following Sentence 2. However, even following Sentence 1 , participants used a singular pronoun nearly $50 \%$ of the time. This result demonstrates that although the conjoined NP structure may lead to an increased preference for a plural pronoun, it in no way eliminates the use of singular pronouns. This raises a question about the relative accessibility of the individual conjuncts and the use of singular and plural pronouns during on-line processing of texts.

Very little research has used on-line measures to investigate the relative ease of processing pronouns whose antecedents are in a conjoined phrase. Clifton and Ferreira (1987) found that a continuation sentence with the plural pronoun they referring to the pair of entities was read no faster following Sentence 1 than following Sentence 2. They took this to suggest that the pronoun found its antecedents in a discourse representation in which Aileen and Steve are represented as a couple, rather than in a representation of the syntactic form of the sentence. In the present paper, we will focus on the processing of singular pronouns following a conjoined phrase, with the goal of learning about the availability of the individual conjuncts and other discourse entities as antecedents. In an unpublished master's thesis, Huitema (1989) presented evidence suggesting that individual proper names were equally available as antecedents when they were in a conjoined phrase (Mary and John left the party at different times. Consequently, she got a ride from a friend of hers) as when they were in separate phrases (Mary saw John leave the party at twelve $o$ 'clock...). Huitema's eyetracking experiment showed equally fast reading times on and following the pronoun (she, in the example) in the two cases. However, his data are not definitive. The conjoined phrase sentences were designed to separate the two individuals in a "mental model" representation of the discourse. If pronouns do find their antecedents in a discourse representation (rather than the surface syntactic structure), then Huitema's manipulation would result in comparable antecedent representations in both the conjoined and the separate cases. Further, as Huitema has pointed out, his experiment had possible technical problems resulting from infrequent fixations on the pronouns and from the fact that pronouns frequently occurred near the beginning of a display line, where fixation duration could be influenced by the return sweep of the eye from the previous line (see Rayner, Sereno, Morris, Schmauder, \& Clifton, 1989).

There is some positive evidence that using a singular pronoun to refer to one of two conjoined names results in an increase in processing time. Garrod and Sanford (1982) used vignettes like the following ones:

(3) a. It was a fine Saturday morning.
b. John and Mary went into town.
c. She/they/Mary wanted some new clothes.

(4) a. The library was quite full.

b. Linda and Jim could not sit down anywhere.

c. The librarian told him/them/Jim to wait.

In all cases, the syntactic and discourse structure encouraged participants to consider the set of individuals as a single discourse entity. Garrod and Sanford (1982) found that using a singular pronoun to reference a single conjunct (i.e., she to Mary, or him to Jim) was more disruptive than using a plural pronoun to collectively refer to both NPs (i.e., they to John and Mary, and them to Linda and Jim). However, the disruption caused by the antecedent being in a conjoined NP (which we will refer to as the "conjunction cost") was significant only when the pronoun was in a nonsubject position, as in (Sentence 4c).

There are two features of Garrod and Sanford's (1982) experiment that are particularly noteworthy. First, conjunction cost was significant only when the pronoun was in a nonsubject position. Garrod and Sanford (1982) have suggested that there may be different antecedent retrieval processes for pronouns in the subject position than for pronouns in a nonsubject position. However, it is possible that their Experiment 2 simply failed to detect a true effect for subject pronouns. Second, in Garrod and Sanford's (1982) experiment, the singular pronoun always referenced the second NP of the conjoined phrase. Gernsbacher's work on the advantage of first mention (Gernsbacher \& Hargreaves, 1988; Gernsbacher, Hargreaves, \& Beeman, 1989) suggests that the first NP may be more available than the second. It is possible that referencing the second, less accessible NP of the conjoined phrase inflated the apparent difficulty of referring to one of two conjoined NPs.

Current evidence thus suggests that there are at least limited circumstances under which splitting a conjoined NP to get at an antecedent for a pronoun may disrupt processing. We present experiments that are designed to further explore the range of these circumstances. Our first experiment was designed simply to establish the empirical effect of conjunction cost. It incorporated two comparisons, each of which would indicate a conjunction cost by comparing a different baseline condition with the reading time of a singular pronoun whose antecedent was one of two conjoined proper names (Pam and Sam). In the first baseline condition, the antecedent was a singular proper name that replaced the conjoined pair of names in the preceding sentence. In the second, the antecedent was a singular definite description (e.g., the usher) that appeared in the same sentence as the conjoined pair of names. In each case, longer reading times when the pronoun had to find its antecedent within the conjoined phrase would indicate the presence of conjunction cost. The (first) proper name and the descriptive noun always named (or were biased toward naming) individuals of the same sex, so the content of the sentence with the pronoun, rather than the pronoun's gender, disambiguated the pronoun's antecedent. Since Experiment 1 succeeded in demonstrating conjunction cost, the second experiment explored possible mechanisms for 
Table 1

Sample Passages for Each Combination of Proper Name Type, Antecedent Position, and Antecedent Type: Experiment 1

Lead in: The cinema was quite full for the movie premier.

1. STAN and Pam asked the usher for assistance. He appreciated all of the help. Conjoined names, subject-antecedent, proper name

2. The USHER helped Stan and Pam find a seat. He located a few seats in the front. Conjoined names, subject-antecedent, noun description

3. The usher helped STAN and Pam find a seat. He appreciated all of the help. Conjoined names, nonsubject-antecedent, proper name

4. Stan and Pam asked the USHER for assistance. He located a few seats in the front. Conjoined names, nonsubject-antecedent, noun description

5. STAN asked the usher for assistance. He appreciated all of the help. Simple, subject-antecedent, proper name

6. The USHER helped Stan find a seat. He located a few seats in the front Simple, subject-antecedent, noun description

7. The usher helped stan find a seat. He appreciated all of the help. Simple, nonsubject-antecedent, proper name

8. Stan asked the USHER for assistance. He located a few seats in the front. Simple, nonsubject-antecedent, noun description

Coda: The usher then walked back to the ticket office

Note--In the table (but not in the experimental text), the antecedent appears in capital letters.

the conjunction cost effect, manipulating (among other things) whether the gender of the pronoun disambiguated its antecedent.

\section{EXPERIMENT 1}

Experiment 1 was directed primarily at clarifying the empirical facts about when finding an antecedent within a conjoined NP will disrupt processing. It used texts like the passages shown in Table 1. In the antecedent sentence, two or three individuals were introduced. In the conjoined conditions, the antecedent sentence introduced two individuals with proper names (Stan and Pam) and one individual with a definite noun description (the usher), whereas the simple conditions introduced a single character with a proper name (Stan) and another with a definite noun description (the usher). These entities were introduced either in the subject position or in a nonsubject position. The antecedent sentence was always followed by a sentence with a singular pronoun subject that referred to either the first proper name NP of the conjoined phrase or the noun description.

This experiment differed from previous research in a few important ways. Garrod and Sanford's (1982) findings and Gernsbacher's advantage of first mention (e.g., Gernsbacher \& Hargreaves, 1988) suggest that the most rigorous test of the hypothesis that splitting a conjoined phrase is disruptive is to make the first NP of the conjoined phrase the antecedent. Thus, when the antecedent was from the conjoined phrase, it was always the first NP. Second, the pronoun was always in the subject position, a position in which Garrod and Sanford (1982) failed to find a significant cost of splitting a conjoined phrase. We reasoned that if we succeeded in finding conjunction cost for a subject pronoun, we could generalize our conclusions to pronouns in nonsubject positions, where Garrod and Sanford (1982) found significant cost. Third, as noted earlier, processing difficulty was assessed by comparing reading times when the pronoun referred to the first conjunct (Stan from Stan and Pam) with reading times when it referred to the named character in the simple conditions (Stan alone) and when it referred to the noun description (e.g., the usher). Neither of the latter two conditions required splitting a conjoined phase to find an antecedent. The first of these two conditions keeps syntactic position of the antecedent the same as in the condition where a conjoined phrase had to be split, and the second keeps the antecedent sentence the same. Finally, to establish whether a disruption in reading time varied as a function of accessibility of the antecedent information, the syntactic role of the pronoun was held constant and the syntactic role of the antecedent was manipulated. Specifically, the antecedent was either in the subject position or in a nonsubject position. Previous research (e.g., Gordon et al., 1990) has demonstrated that the subject of a sentence is generally perceived as the most prominent discourse entity in the sentence and is often taken as the antecedent of a subsequent pronominal reference. Thus, we expected that a pronominal reference to an antecedent in the subject position would be completed more quickly and easily than a pronominal reference to an antecedent in a nonsubject position.

\section{Method}

Participants. Forty University of Massachusetts undergraduates participated in return for course credit. All participants were native English speakers.

Materials. Forty-eight short narrative texts were constructed. An example is presented in Table 1 . The texts were 3 to 7 sentences in length ( $M=4.3$ sentences). The opening sentence(s) always established the setting, but never explicitly mentioned any of the characters. The antecedent sentence immediately followed the opening. The factors of proper name type (conjoined vs. simple) and antecedent position (subject vs. nonsubject positions) were combined to produce four versions of the antecedent sentence. In the conjoined versions, the sentence introduced three characters; two were introduced with proper names and conjoined with and, and the third character was introduced with a noun description. The noun description 
Table 2

Mean Whole-Sentence Reading Times (in Milliseconds), Experiment 1

\begin{tabular}{|c|c|c|}
\hline Pronoun Antecedent & Conjoined Names & Simple Name \\
\hline \multicolumn{3}{|c|}{ Subject Antecedent Conditions } \\
\hline Proper name $(1,5)$ & 2,000 & 1,784 \\
\hline Noun description $(2,6)$ & 1,910 & 1,883 \\
\hline \multicolumn{3}{|c|}{ Nonsubject Antecedent Conditions } \\
\hline Proper name $(3,7)$ & 2,145 & 1,930 \\
\hline Noun description $(4,8)$ & 1,972 & 1,947 \\
\hline \multicolumn{3}{|c|}{ Means } \\
\hline Proper name $(1,3,5,7)$ & 2,073 & 1,857 \\
\hline Noun description $(2,4,6,8)$ & 1,941 & 1,915 \\
\hline
\end{tabular}

Note--Sentence-form numbers from Table 1 are indicated parenthetically in the left column.

was always gencer biased; half of the noun descriptions were male biased and the remaining half were female biased. The first NP of the conjoined phrase and the noun description were always the same gender (i.e., Stan and the usher in Table 1) to permit the pronoun to refer ambiguously to either one (with disambiguating content following the pronoun). To create the simple versions, the second proper name character was eliminated from the conjoined phrase, producing antecedent sentences with one proper name character and one noun description. Finally, the proper name characters were either in the subject position or in a nonsubject position. When the proper name characters were in a nonsubject position, the noun description always served as the subject of the antecedent sentence.

One of two versions of the pronoun sentence immediately followed the antecedent sentence. The target pronoun was always in the subject position. In one version, the pronoun sentence referred to the first proper name character (average sentence length $=39$ characters), whereas the other version made reference to the noun description (average sentence length $=38$ characters). Because the first name character and the noun description were the same gender, the pronoun was ambiguous and the remaining portion of the sentence was needed to identify the appropriate antecedent.

In addition to the 48 experimental texts, there were 30 filler passages that varied in length and in the number of protagonists that were introduced. Following half of the texts (including 24 experimental texts), participants were given a two-choice wh-question to ensure accurate comprehension. Half of the questions following the experimental passages (12) required knowledge of the characters' actions and in some cases resolution of the pronoun, whereas the remaining questions for the experimental and filler passages queried other aspects of the narrative. The question for the passage in Table 1 was as follows:

Stan and Pam asked the usher for assistance?

Stan

The correct answer for questions that required knowledge of the actions of the character(s) depended on the version of the text that was presented.

Design. Combining antecedent position (subject vs. nonsubject), proper name type (conjoined vs. simple), and antecedent type (proper name character vs. noun description character) produced eight conditions. For each participant, the experimental texts were randomly assigned to the eight conditions, with two constraints: Each participant saw six passages in each condition, and across participants, each passage occurred in each condition an equal number of times.

Procedure. Each participant was tested individually in a session that lasted approximately $40 \mathrm{~min}$. All materials were presented on a computer monitor controlled by a microcomputer. Participants were instructed to place their right index finger on a key corresponding to the right side of the computer monitor and their left index finger on a key corresponding to the left side of the monitor. Each passage began with a READY message in the center of the screen. Participants were instructed to press the right key when they were ready to begin a passage; each press of the key erased the current line of text and presented the next line. Comprehension time was calculated as the time between keypresses. Participants were instructed to read at a comfortable pace. Immediately following half of the passages, the cue QUESTION was presented for $1,000 \mathrm{msec}$, followed by a comprehension question about the passage. Participants answered the questions by pressing the key (i.e., right or left) corresponding to the correct answer. They were told that answering the questions was the most important part of their task and that they should try to answer the questions as quickly and as accurately as possible. On those trials in which the question was answered incorrectly, the word ERROR was presented for 1,000 msec. Each session began with three practice passages to make sure that participants understood the procedure.

\section{Results}

In the experiments reported in this paper, $F_{1}$ refers to tests against an error term based on subject variability and $\mathrm{F}_{2}$ refers to tests against an error term based on item variability. Results reported as significant are at the .05 level or beyond unless otherwise indicated. In Experiment 1, reading times less than $200 \mathrm{msec}$ or greater than $8,000 \mathrm{msec}$ were considered outliers and eliminated from the analyses. This eliminated less than $1 \%$ of the reading times.

The mean reading times for the pronoun sentences are presented in Table 2. A 2 (antecedent type: proper name vs. noun description) $\times 2$ (name type: conjoined vs. simple) $\times 2$ (position: subject vs. nonsubject) analysis of variance (ANOVA) was performed. The most notable aspect of the data was the fact that reading time was substantially longer $(2,073 \mathrm{msec})$ when the pronoun referred to the first of two conjoined proper names than in any other condition. This one long time resulted in a significant interaction between the factors of name and noun antecedent and conjoined and simple name sentences $\left[F_{1}(1,39)=7.44\right.$, $\left.M S_{\mathrm{e}}=96,259 ; F_{2}(1,47)=10.38, M S_{\mathrm{e}}=86,258\right]$ and a significant main effect of conjoined versus simple name sentences $\left[F_{1}(1,39)=10.87, M S_{\mathrm{e}}=107,370 ; F_{2}(1,47)=14.26\right.$, $\left.M S_{\mathrm{e}}=96,545\right]$.

Two sets of planned contrasts focused on this one apparently long time. The first contrast analyzed data from all the texts in which the pronoun took a proper name as an antecedent to determine whether accessing a proper name within a conjoined phrase was more disruptive than accessing the same proper name when it was presented by itself (see Figure 1, top panel). Time to read the pronoun sentence was significantly longer when the antecedent was an NP of a conjoined phrase than when it was a nonconjoined antecedent $\left[2,073\right.$ vs. $1,857 \mathrm{msec} ; F_{1}(1,39)=$ $\left.14.16, M S_{\mathrm{e}}=131,070 ; F_{2}(1,47)=23.30, M S_{\mathrm{e}}=96,442\right]$. Planned comparisons revealed that this was true both when the antecedent was in the subject position $[2,000 \mathrm{vs}$. 1,$784 ; F_{1}(1,39)=9.55, M S_{\mathrm{e}}=195,366 ; F_{2}(1,47)=12.93$, $\left.M S_{\mathrm{e}}=173,140\right]$ and when it was in a nonsubject position $\left[2,145\right.$ vs. 1,$930 ; F_{1}(1,39)=6.50, M S_{\mathrm{e}}=283,536 ; F_{2}(1,47)=$ $\left.10.93, M S_{\mathrm{e}}=206,221\right]$

The second contrast determined whether accessing one of two conjoined names was more disruptive than access- 

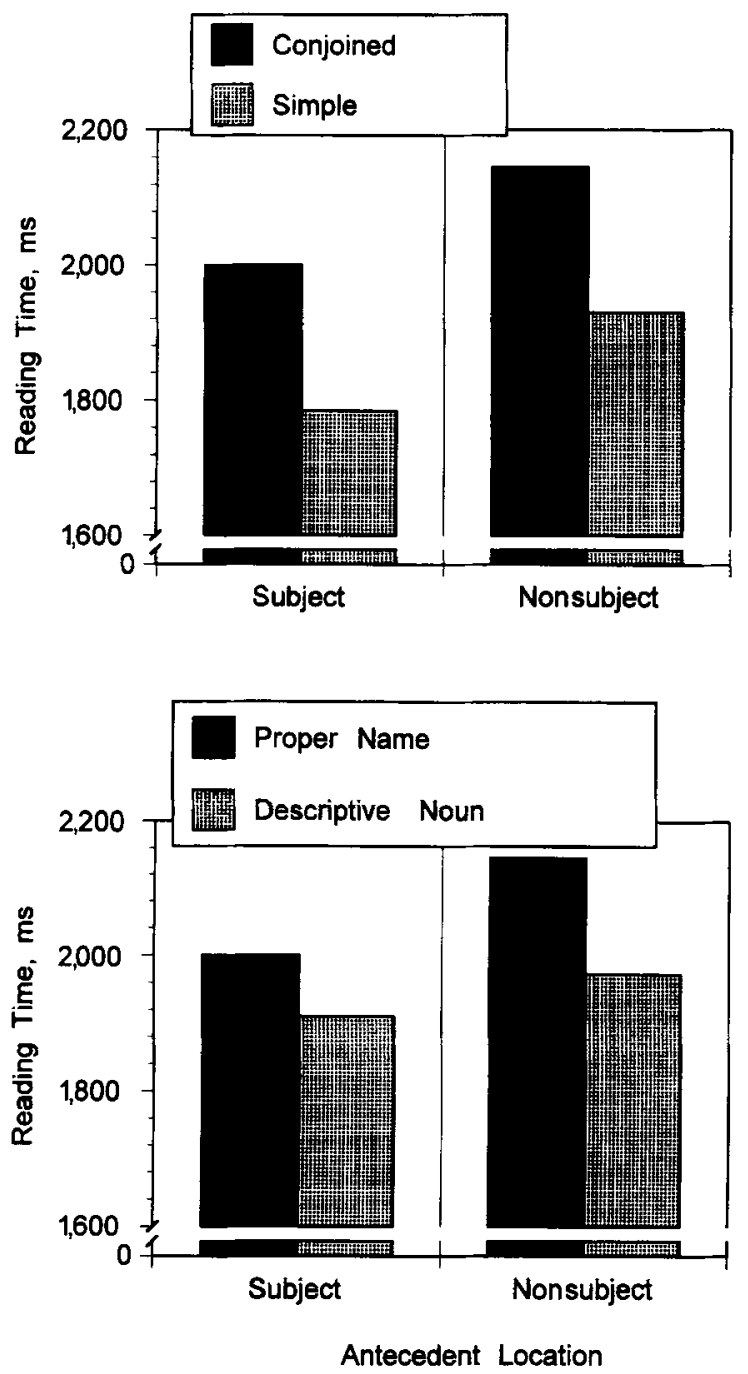

Figure 1. Whole-sentence reading times, Experiment 1. Top panel: conjoined versus simple proper name antecedent. Bottom panel: proper name versus descriptive noun antecedent.

ing a nonconjoined noun description (Figure 1, bottom panel). Reading times were longer when the pronoun sentence referred to the first NP of the conjoined phrase than when it referred to the noun description $[2,073$ vs. 1,941 ; $F_{1}(1,39)=5.89, M S_{\mathrm{e}}=117,630 ; F_{2}(1,47)=6.96, M S_{\mathrm{e}}=$ $121,172]$. Planned comparisons revealed that this was true when the antecedent was in a nonsubject position $[2,145$ vs. 1,$972 ; F_{1}(1,39)=6.89, M S_{\mathrm{e}}=174,175 ; F_{2}(1,47)=5.45$, $\left.M S_{\mathrm{e}}=270,115\right]$. Although the difference was in the predicted direction when the antecedent was in the subject position, the effect did not reach significance $(2,000 \mathrm{vs}$. $1,910 \mathrm{msec} ; F_{\mathrm{s}}<1.6$-possibly reflecting nothing more than a Type II error).

In addition to showing effects of having to find a pronoun antecedent within a conjoined NP, reading times were significantly shorter when the antecedent was in the subject position than when it was in a nonsubject position $\left[1,894\right.$ vs. 1,$998 ; F_{1}(1,39)=9.95, M S_{\mathrm{e}}=87,223 ; F_{2}(1,47)=$ $\left.5.64, M S_{\mathrm{e}}=191,513\right]$. This result echos a previously observed advantage of subject antecedents, as discussed earlier.

\section{Discussion}

Experiment 1 demonstrates that splitting a conjoined phrase to access a single NP antecedent is more disruptive than accessing a nonconjoined antecedent. Participants read the target sentences more slowly when the pronoun referred to a proper name in a conjoined phrase than when it referred to a nonconjoined proper name character or when it referred to a character introduced by a descriptive noun. In both cases, the conjunction cost was numerically present in both the subject and nonsubject positions and was significant in three of four contrasts.

The results of Experiment 1 extend the findings of Garrod and Sanford (1982) in several ways. First, the conjunction cost was significant when the singular pronoun was in the subject position, whereas Garrod and Sanford (1982) found a significant conjunction cost only when the pronoun was in a nonsubject position. Second, conjunction cost was present when the antecedent was the first NP of a conjoined phrase, suggesting that the significant disruption found by Garrod and Sanford (1982) was not due solely to a possible disadvantage in accessibility of the second NP. Finally, consistent with previous findings (e.g., Clifton \& Ferreira, 1987; Gordon et al., 1990), there was an effect of syntactic role. Pronouns were processed more quickly when the antecedent was in the subject position than when the antecedent was in a nonsubject position.

Given the existence of a robust effect of having to find an antecedent in a conjoined phrase, we can raise the question of the possible mechanisms behind the effect. We will propose two, and evaluate them in the following experiment. Each assumes that a pronoun finds its antecedent in a discourse representation or situational model (see Garrod \& Sanford, 1994) rather than in the surface linguistic structure. The first mechanism claims that a discourse entity corresponding to the pair of individuals mentioned in the conjoined phrase interferes with accessing or using a single individual as the antecedent of a pronoun. The second mechanism claims that the discourse entity corresponding to the descriptive noun interferes with accessing a proper name individual as the antecedent. Clearly, the two mechanisms are not mutually exclusive.

We will term the first mechanism "splitting." Splitting could arise from several sources. One possibility is that a reader sets up a separate discourse token corresponding to the complex referent object of the pair of characters (Eschenbach, Habel, Herweg, \& Rehkämper, 1989; see also Sanford \& Moxey, 1995, for discussion). The existence of this token could interfere with access to presumed discourse tokens of the individual, or the complex-referent token could even substitute for individual tokens, thus requiring decomposition to make individuals available as antecedents. Another possibility is that the pair of characters could be mapped onto a single discourse role (Sanford \& Moxey, 1995). If pronouns find their actual an- 
tecedents via reference to discourse roles, then requiring that a pronoun take a single individual as an antecedent will require that the two individuals mapped onto the discourse role be differentiated. The process of differentiation presumably takes time.

The second mechanism, "bonding," derives from Sanford and Garrod's work (Sanford, 1985; Sanford \& Garrod, 1989). It claims that a pronoun is initially assigned in a tentative fashion to a salient discourse entity that satisfies the morphological requirements of the pronoun (gender and number in English). This bond is interpreted as an anaphoric relation and evaluated for its appropriateness only at a later stage of processing, when new material demands an interpretation (see Sanford \& Garrod, 1989, p. 255). In the Experiment 1 materials, the noun description term and the (first) proper name both satisfied the morphological requirements of the pronoun. Sanford et al. (1988; see also Garrod, Freudenthal, \& Boyle, 1993) have argued that proper names typically designate main characters, which are more accessible as pronoun antecedents than are secondary (nonproper name) characters. Thus, everything else being equal, the pronoun would presumably bond with the proper name character, resulting in easy interpretation of an anaphoric relation between pronoun and proper name. However, when the proper name character is embedded within a conjoined NP, it might be less available for bonding (for reasons similar to those advanced in the discussion of the splitting mechanism, or simply because it does not constitute a full phrase in the syntactic structure of the sentence, if bonding takes place at a superficial linguistic level). If the pronoun is therefore bonded with the noun description character in the conjoined proper name condition, interpreting the pronoun as having a single proper name antecedent will require breaking the initial bond at a cost in processing time.

The results of Experiment 1 could largely be accounted for by either the splitting or the bonding mechanisms. Splitting claims that increased reading times in the proper name/conjoined name condition reflect the time to break down the compound NP to obtain the singular NP antecedent. Bonding claims that the increased times reflect the requirement to give up the preferred bond to the descriptive noun character. And, of course, the increased time may reflect both processes. Experiment 2 attempted to collect independent evidence for each process.

\section{EXPERIMENT 2}

The bonding mechanism attributes the processing disruption found in Experiment 1 to the fact that both the noun description and the first conjunct match the gender and number of the pronoun. According to this mechanism, if the pronoun matched only the first conjunct, the pronoun could not bond to the noun description character, eliminating interference from it. If the Experiment 1 disruption was due totally to bonding, disruption should be eliminated when the pronoun is morphologically appropriate only to a single proper name. Such a condition was added in Experiment 2 (see Table 3, Conditions 5 and 7). If disruption is present in this condition, it could be taken as evidence for the existence of another process, such as the splitting process we have described. However, even if other factors (such as splitting) operate, greater disruption in the ambiguous antecedent/proper name condition (Conditions 1 and 3, Table 3) than in the unambiguous antecedent/proper name condition (Conditions 5 and 7) would indicate the operation of bonding.

A positive test of the operation of the splitting process can also be made. If participants do establish an inappropriate bond between the pronoun and the noun description (at least in Conditions 1 and 3, Table 3), they cannot begin breaking the bond until they read material that disambiguates a sentence. In our test items, this is always material that follows the pronoun. Thus, according to the bonding mechanism, disruption will be delayed until disambiguating information is read. On the other hand, the splitting mechanism could in principle result in disruption as soon as an unambiguous pronoun is read, if the costly process of breaking down a complex discourse entity to obtain an appropriate antecedent begins immediately. Evidence of disruption immediately upon reading the pronoun (in Conditions 5 and 7), then, will be positive evidence for the operation of what we have called the splitting mechanism. (Evidence of disruption in the ambiguous condition after the disambiguating information has been processed is, of course, consistent with both hypotheses. In the ambiguous condition, neither splitting nor breaking an inappropriate bond is justified until the pronoun is disambiguated.)

Experiment 2 tested these predictions with materials adapted from Experiment 1 . We created a new set of conditions in which the order of the first and second conjuncts was switched so that the first conjunct and the noun description differed in gender. In this case, a singular pronoun referring to the first conjunct matched only that NP, and not the noun description; these conditions are referred to as the "unambiguous antecedent" conditions. The conditions used in Experiment 1, in which the first conjunct and the noun description both matched the gender and number of the pronoun, are referred to as "ambiguous antecedent" conditions. Table 3 presents a sample passage exemplifying each of these conditions and indicates the sentence regions that were analyzed. ${ }^{2}$

In Experiment 2, participants read the narrative texts while their eye movements were monitored. Eyetracking methodology provides a moment-by-moment record of processing (Rayner \& Sereno, 1994). When the target regions are larger than a single word, like those in Experiment 2, Rayner and Sereno (1994; Rayner et al., 1989) have suggested using multiple eyetracking measures. Thus, we report first-pass and second-pass reading times for each of several regions of the sentences (and in cases where these measures left some ambiguity, we report reading times as well). Following Rayner and Sereno (1994; Rayner \& Pollatsek, 1989; Rayner et al., 1989), first-pass reading time for a region is defined as the sum of all fixations in a region before the first fixation out of that region 
Table 3

Sample Passage, Each Combination of Antecedent Position, Type, and Possibility: Experiment 2

Lead in: The cinema was quite full for the movie premier

1. PAM and Stan asked the usherette for assistance. /She quickly/ followed the usherette/ to the seats./ Ambiguous, subject, proper name

2. The usheretTe helped Pam and Stan find some seats. /She quickly/ found a couple of seats/ for them./ Ambiguous, subject, noun description

3. The usherette helped PAM and Stan find some seats. /She quickly/ followed the usherette/ to the seats./ Ambiguous, nonsubject, proper name

4. Pam and Stan asked the USHERETTE for assistance. /She quickly/ found a couple of seats/for them./ Ambiguous, nonsubject, noun description

5. STAN and Pam asked the usherette for assistance. /He quickly/followed the usherette/ to the seats./ Unambiguous, subject, proper name

6. The USHERETTE helped Stan and Pam find some seats. /She quickly/found a couple of seats/for them./ Unambiguous-control, subject, noun description

7. The usherette helped stan and Pam find some seats. /He quickly/ followed the usherette/ to the seats./ Unambiguous, nonsubject, proper name

8. Stan and Pam asked the USHERETTE for assistance. /She quickly/ found a couple of seats/ for them./ Unambiguous-control, nonsubject, noun description

Coda: Then the usherette returned to the ticket office.

Note-Antecedent is presented in capital letters. Ambiguous: The first conjunct and the noun description matched in number and gender. Unambiguous: The first conjunct and noun description did not match in number and gender. Unambiguous-control items are actually ambiguous in that the second conjoined name as well as the noun description was appropriate in gender for the pronoun.

(i.e., the first fixation in a following region or a regression back to a previous region). Trials on which the region was not fixated in the initial pass through the sentence were eliminated. Second-pass reading time is the time spent rereading a region. Trials on which a region was not reread contributed a zero score to second-pass time. The immediate impact of splitting a conjoined phrase can be evaluated by the first-pass reading time measure and additional processing can be measured with the second-pass measure.

In the materials used in Experiment 2, Analysis Region 1 always included the pronoun and one or two following neutral words to measure processing of the pronoun before any disambiguating material was fixated. Analysis Region 2 contained the semantically disambiguating material. It always included the main verb and generally the first argument of the verb as well (but in the case of a few long verbs, it contained nothing other than the verb). Analysis Region 3 consisted of the next few words up to a natural phrase break, never fewer than eight characters and occasionally extending to the end of the sentence. It generally sharpened the disambiguation of the pronoun antecedent. We broke the postpronoun segment into two regions in order assess how quickly disambiguating information was used.

Experiment 2 was expected to identify just where in the string of words any disruption effects appear. There should be an observable conjunction cost: Reading times should be longer when the antecedent is a single NP in a conjoined phrase than when it is the nonconjoined noun description. If bonding is the only mechanism that results in conjunction cost, no such cost should be observed in the unambiguous antecedent conditions (Conditions 5 and 7, Table 3). In these conditions, the pronoun (he) should bond only with the first conjunct (Stan), and there is no inappropriate bond to reject. However, in the ambiguous an- tecedent conditions (Conditions 1 and 3 ), there should still be a conjunction cost because it is possible to establish an inappropriate bond between the pronoun and the noun description. In contrast, the splitting hypothesis predicts a conjunction cost regardless of whether the pronoun matches one NP or two. In both cases, successful resolution requires breaking down the conjoined NP to access a single NP. If both mechanisms operate, then a conjunction cost is expected in both ambiguous (Conditions 1 and 3 ) and unambiguous (Conditions 5 and 7 ) conditions, larger in the former than the latter.

Because Experiment 2 permitted us to measure the time to read the pronoun (plus some nondisambiguating adverbial material) separately from the disambiguating information, the locus of disruption can be determined. The bonding mechanism permits disruption to begin only in the region after the pronoun (in the ambiguous antecedent condition, Conditions 1 and 3 of Table 3 ) when disambiguating information is presented. The splitting mechanism, on the other hand, could permit disruption to occur in the first region, where participants are processing the pronoun and presumably accessing the antecedent. Disruption may appear only in the unambiguous antecedent condition (Conditions 5 and 7) since readers have no reason to decompose the conjoined phrase in the ambiguous antecedent condition.

As in Experiment 1, the syntactic role of the antecedent information was also varied. Subject antecedents should be more available than nonsubject antecedents, but we have no compelling reason to predict interactions between antecedent position and the remaining factors.

\section{Method}

Participants. Forty volunteers from the University of Massachusetts community participated in return for course credit or $\$ 5$. 
Table 4

Mean First-Pass Reading Times (in Milliseconds), Experiment 2

\begin{tabular}{|c|c|c|c|c|c|c|}
\hline \multirow[b]{2}{*}{ Pronoun Antecedent } & \multicolumn{2}{|c|}{ Region 1 (Pronoun) } & \multicolumn{2}{|c|}{ Region 2 (Initial Disambiguating) } & \multicolumn{2}{|c|}{ Region 3} \\
\hline & Ambiguous & Unambiguous & Ambiguous & Unambiguous & Ambiguous & Unambiguous \\
\hline \multicolumn{7}{|c|}{ Subject Antecedent Conditions } \\
\hline Proper name $(1,5)$ & 353 & 355 & 352 & 380 & 429 & 418 \\
\hline Noun description $(2,6)$ & 352 & 347 & 327 & 355 & 391 & 392 \\
\hline \multicolumn{7}{|c|}{ Nonsubject Antecedent Conditions } \\
\hline Proper name $(3,7)$ & 352 & 379 & 347 & 370 & 431 & 396 \\
\hline Noun description $(4,8)$ & 352 & 340 & 333 & 332 & 383 & 392 \\
\hline \multicolumn{7}{|c|}{ Means } \\
\hline Proper name $(1,3,5,7)$ & 353 & 367 & 349 & 375 & 430 & 407 \\
\hline Noun description $(2,4,6,8)$ & 352 & 344 & 330 & 344 & 387 & 392 \\
\hline
\end{tabular}

Note-Parenthetical numbers in left column refer to sentence condition numbers in Table 3 .

All participants were native English speakers and had normal vision or wore soft contact lenses.

Materials. The 48 texts from Experiment 1 were modified and used in Experiment 2. An example is presented in Table 3. The texts were modified in the following ways. First, only the conjoined phrase versions of the texts were used (the single proper name conditions were eliminated). Unambiguous antecedent conditions were constructed from the ambiguous antecedent conditions by switching the order of the proper name characters in the conjoined phrase and changing the gender of the pronoun in the next sentence. In Table 3 , the order of the proper name characters in the ambiguous antecedent versions was Pam and Stan followed by the usherette, whereas the order of names in the unambiguous antecedent versions was Stan and Pam followed by the usherette. Second, some of the noun descriptions were changed to strengthen the gender bias. In some cases, these changes made it necessary to modify other parts of the passage, including the pronoun sentence. As in Experiment 1, the antecedent sentence included the name characters conjoined with and and the noun description. The proper name characters were either in the subject position or in a nonsubject position. When the conjoined phrase was in a nonsubject position, the noun description was always in the subject position. In the ambiguous antecedent versions of the antecedent sentence, the first conjunct in the conjoined phrase and the noun description were the same gender, whereas in the unambiguous antecedent versions, the first conjunct and the noun descriptions differed in gender.

The pronoun sentence was modified in the following way. Each sentence was revised to include one more neutral words (usually an adverbial phrase, but sometimes an uninformative verb) immediately following the pronoun. The neutral words never biased the interpretation of the pronoun and were consistent with the actions and feelings of all characters in the story. The first few words following these neutral words served to disambiguate the pronominal reference in the ambiguous pronoun condition.

Design. Combining antecedent position (subject vs. nonsubject), number of possible antecedents (ambiguous vs. unambiguous antecedent--really, whether or not the pronoun matched the noun description character in gender, see note 2 ), and antecedent type (proper name character vs. noun description character) produced eight conditions. For each participant, the experimental texts were randomly assigned to the eight conditions with two constraints: Each participant saw six passages in each condition, and across participants, each passage occurred in each condition an equal number of times.

Apparatus. Eye movements were recorded from the right eye using a Fourward Technologies Dual Purkinje Eyetracker. Resolution of the eyetracker is reported to be $10^{\prime}$ of arc. The eyetracker was interfaced with a microcomputer that controlled all phases of the experiment. Eye position was sampled every millisecond. Onset of a fixation was defined as the point when five successive samples each differed from the sample taken $5 \mathrm{msec}$ earlier by less than one third of a character space. The onset of a saccade was defined as the point when three consecutive samples each differed from the prior sample by at least one third of a character space.

The passages were displayed in standard upper- and lowercase format using yellow characters on a black background. Characters were made up from a $5 \times 8$ dot matrix and were separated by 3 dots horizontally and 6 dots vertically. Three horizontal character spaces equaled $1^{\circ}$ of visual angle and the vertical distance between lines was about 1.5 line spaces, which was equal to $1.5^{\circ}$ of visual angle. The brightness of the monitor was adjusted to a comfortable level for each participant. Participants' eyes were $80 \mathrm{~cm}$ from the monitor and viewing was binocular. The experimental texts occupied three to seven lines and the maximum line length was 72 characters. To optimize the accuracy of the eyetracking data, the lines of the texts were arranged so that the target regions occurred in the central region of a line.

Procedure. Each participant was tested individually. A bite bar was made for each participant to help minimize head movements during the experiment. Participants were given a brief description of the eyetracker and were told that the purpose of the experiment was to study how people read. Participants were instructed to read at a comfortable pace. They were told that half of the passages would be followed by a two-choice alternative $w h$-question. Once the instructions were understood, the eyetracker was calibrated.

Before participants read each passage, a row of five fixation boxes was displayed in which the first line of a text would appear. The participant was instructed to look at the right-most box and then to look at each box to the left until reaching the left-most box, which indicated the position of the first letter in the upcoming text. If the calibration was accurate, the experimenter initiated the trial. After reading the passage, the participant pressed a response key, which cleared the screen. On those trials for which there was a question, the cue QUESTION was presented for $500 \mathrm{msec}$, and then the question and alternatives were presented. Participants responded to the question by pressing the key corresponding to the correct alternative. On those trials in which the question was answered incorrectly, the word ERROR was presented for $1,500 \mathrm{msec}$. The row of five boxes was displayed again, and the next trial was conducted. Halfway through the experiment, participants were given a break. The entire procedure never exceeded $60 \mathrm{~min}$.

\section{Results}

First-pass and second-pass reading times are presented in Tables 4 and 5, respectively. Fixations shorter than $140 \mathrm{msec}$ or longer than $800 \mathrm{msec}$ were eliminated from the analyses. ${ }^{3}$ A 2 (number of possible antecedents: unambiguous 
Table 5

\begin{tabular}{|c|c|c|c|c|c|c|}
\hline \multirow[b]{2}{*}{ Pronoun Antecedent } & \multicolumn{2}{|c|}{ Region I (Pronoun) } & \multicolumn{2}{|c|}{ Region 2 (Initial Disambiguating) } & \multicolumn{2}{|c|}{ Region 3} \\
\hline & Ambiguous & Unambiguous & Ambiguous & Unambiguous & Ambiguous & Unambiguous \\
\hline \multicolumn{7}{|c|}{ Subject Antecedent Conditions } \\
\hline Proper name $(1,5)$ & 59 & 54 & 45 & 27 & 44 & 15 \\
\hline Noun description $(2,6)$ & 33 & 51 & 49 & 28 & 26 & 31 \\
\hline \multicolumn{7}{|c|}{ Nonsubject Antecedent Conditions } \\
\hline Proper name $(3,7)$ & 69 & 67 & 54 & 36 & 56 & 32 \\
\hline Noun description $(4,8)$ & 38 & 38 & 23 & 35 & 23 & 28 \\
\hline \multicolumn{7}{|c|}{ Means } \\
\hline Proper name $(1,3,5,7)$ & 64 & 60 & 50 & 32 & 50 & 30 \\
\hline Noun description $(2,4,6,8)$ & 35 & 45 & 36 & 32 & 25 & 30 \\
\hline
\end{tabular}

Note-Parenthetical numbers in left column refer to sentence condition numbers in Table 3 .

vs. ambiguous) $\times 2$ (antecedent type: proper name vs. noun description) $\times 2$ (antecedent position: subject vs. nonsubject) $\times 3$ (region: $1,2,3$ ) ANOVA was completed on the first- and second-pass reading time measures. Consider first-pass times first. Pooled over the three regions to maximize statistical power, reading times were longer when the antecedent was part of a conjoined pair of proper names than when it was a noun description [ 380 vs. 358 msec, first-pass; $F_{1}(1,39)=12.83, M S_{\mathrm{e}}=9,161$; $\left.F_{2}(1,42)=9.48, M S_{\mathrm{e}}=11,135\right]$. Thus, a conjunction cost was observed in Experiment 2, as in Experiment 1.

The evidence against the operation of a bonding mechanism was clear. First-pass reading time (pooled over regions) showed a $21-\mathrm{msec}$ effect of proper name versus noun description antecedent for ambiguous items ( $377 \mathrm{msec}$ for names, 356 for nouns) and a 23-msec effect for unambiguous items ( 383 vs. $360 \mathrm{msec}$ ). The interaction between antecedent type and ambiguity was nonsignificant $(F<1)$.

Conjunction cost in the region containing the pronoun was limited to the unambiguous condition. The interaction of ambiguity, name/noun, and region-predicted by the splitting but not the bonding hypothesis- -was significant on $F_{2}$ but not $F_{1}$ in the first-pass time measure $\left[F_{1}(1,39)=\right.$ $\left.1.67, M S_{\mathrm{e}}=8,559, p<.20 ; F_{2}(1,47)=4.15, M S_{\mathrm{e}}=4,323\right] .{ }^{4}$ The pattern of first-pass times can be seen in Figure 2. The effect of proper name versus descriptive noun began with a 24-msec difference in Region 1 of the unambiguous condition [significantly greater than zero; $F_{1}(1,39)=3.77$, $\left.M S_{\mathrm{e}}=5,761, p<.06 ; F_{2}(1,47)=5.37, M S_{\mathrm{e}}=6,807\right]$, while the difference was only $1 \mathrm{msec}$ in Region 1 of the ambiguous condition. The name-noun difference appeared strongly in later regions of the ambiguous condition. In Region 3, the name-noun difference appeared to be larger for the ambiguous than for the unambiguous condition, but the difference between these name-noun differences was nonsignificant $(p>.10)$.

Only two effects were significant in the second-pass times. As was observed for first-pass times, there was a significant conjunction cost. Second-pass reading times pooled over the three regions were longer when the antecedent was part of a conjoined pair of names than when it was a noun description $\left[47 \mathrm{vs.} 34 \mathrm{msec} ; F_{1}(1,39)=5.93\right.$, $\left.M S_{\mathrm{e}}=6,686 ; F_{2}(1,47)=5.36, M S_{\mathrm{e}}=8,219\right]$. Second, the interaction between antecedent type (name vs. noun) and ambiguity, which was nonsignificant in first-pass times, approached significance in the second-pass times. The second-pass time difference was $23 \mathrm{msec}$ for ambiguous items and $4 \mathrm{msec}$ for unambiguous items $\left[F_{1}(1,39)=2.94\right.$, $M S_{\mathrm{e}}=7,537, p<.10 ; F_{2}(1,47)=3.47, M S_{\mathrm{e}}=6,396$, $p<.07]$.

In contrast to Experiment 1, there were no significant differences between subject and nonsubject antecedents ( $F<1$ for both first- and second-pass reading times). While the effect of proper name versus noun description on first-pass reading time was approximately the same when the antecedent was in the subject and in a nonsubject position $(F<1)$, the effect of name versus noun on second-pass time was smaller when the antecedent was in the subject position than when it was in a nonsubject position [5 vs. $21 \mathrm{msec} ; F_{1}(1,39)=4.84, M S_{\mathrm{e}}=3,654$; $\left.F_{2}(1,47)=5.42, M S_{\mathrm{e}}=3,973\right]$.

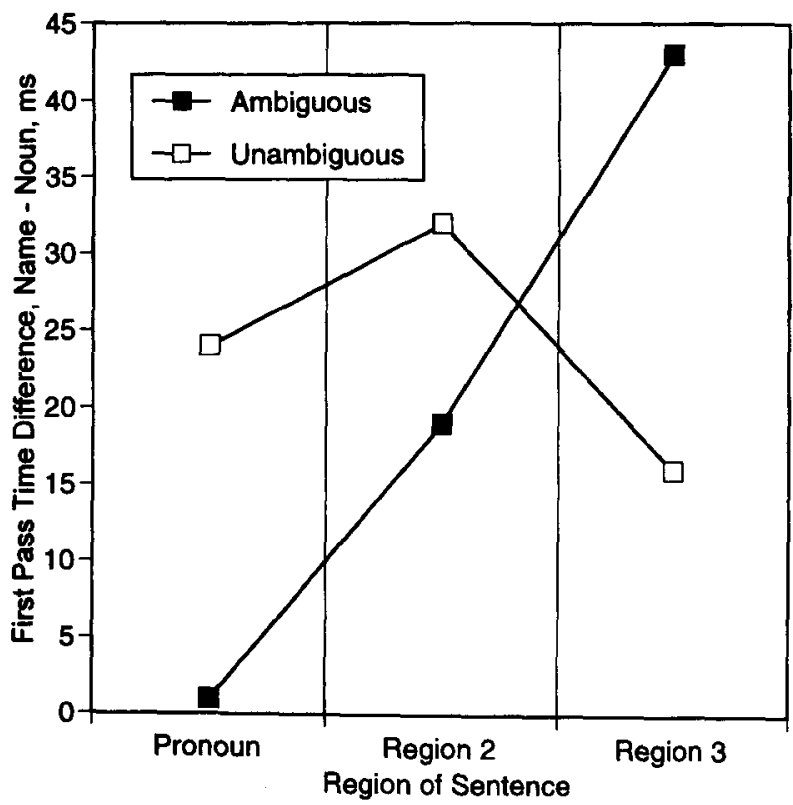

Figure 2. Differences in first-pass reading time (proper name-descriptive noun), Experiment 2. 


\section{Discussion}

The evidence for the operation of the splitting mechanism was quite clear. The early processing cost of finding the antecedent of a pronoun within a conjoined noun phrase was nearly the same in the unambiguous and the ambiguous conditions. Although levels of statistical significance were not fully convincing, one can reasonably conclude that this cost began at the pronoun itself. That is, when no appropriate-sex competitor to a proper name antecedent exists, readers seem to be disrupted by having to find the antecedent within a pair of conjoined names as soon as the pronoun is read.

One need not appeal to the operation of a bonding mechanism to account for the data. The first-pass reading time advantage of a noun description antecedent over a proper name description was nearly identical for ambiguous and unambiguous items. Second-pass time suggested (at a marginal level of significance) that there may be some lingering difficulty in the ambiguous condition, in which a gender-appropriate but implausible noun description antecedent existed. The appearance of this effect in secondpass, but not first-pass, times suggests that it probably reflects some delayed interpretation and evaluation of the gender-appropriate noun description as an alternative antecedent for the pronoun rather than an initial tentative bonding between the two.

\section{GENERAL DISCUSSION}

The present experiments investigated the relative ease of reading a singular pronoun when it must take one of two conjoined NPs as its antecedent. The disruption in processing caused by accessing a single NP of a conjoined phrase is referred to as the "conjunction cost." Experiment 1 demonstrated the robustness of this effect. We found that accessing a single NP of a conjoined phrase was more costly than accessing a nonconjoined NP that was introduced with either a proper name or a definite description. Extending Garrod and Sanford's (1982) results, the present experiments showed that conjunction cost occurred even when the antecedent was the first NP of the conjoined phrase. Finally, the cost was present when the antecedent was in either subject or nonsubject position.

Two possible, but not mutually exclusive, mechanisms were proposed to account for the results of Experiment 1. The splitting hypothesis states that the conjunction cost reflects additional cognitive processes required to split the conjoined phrase to access a single NP antecedent. The bonding hypothesis proposes that a pronoun can be initially associated with an NP that satisfies its morphological requirements (such as the noun description NP in Experiment 1). This bond is later evaluated as a co-reference (antecedent) relation. If it is inappropriate, it must be rejected at some cost in processing.

Experiment 2 sought evidence for both of these mechanisms by comparing cases in which there was only one morphologically appropriate antecedent for a pronoun with cases in which there were two morphologically ap- propriate antecedents. The former cases were called "unambiguous" and contained a noun description phrase that was gender inappropriate for the pronoun, forcing the reader to find an antecedent within the conjoined name phrase. The latter cases were called "ambiguous," and, as in Experiment 1 , contained gender-appropriate potential antecedents both within the conjoined name phrase and as the noun description. Disruption due to inappropriate bonding should appear only in the latter, ambiguous, conditions.

The results provided evidence for the splitting but not the bonding mechanism. Consistent with splitting, there were equivalent conjunction costs in first-pass reading times for the unambiguous and for the ambiguous antecedent conditions. Contrary to bonding, conjunction cost was never significantly larger for the ambiguous cases (in which bonding could contribute to cost) than for the unambiguous cases.

Additional evidence for the operation of splitting came from examining the time course of the conjunction effect. Experiment 2 suggested that conjunction cost appeared immediately at the pronoun in the unambiguous conditions, but not in the ambiguous conditions (which did not differ until after the pronoun region). That is, the cost of finding an antecedent in a conjoined NP appeared as soon as information logically sufficient to specify the antecedent was read, even if this information blocked any possibility of inappropriate bonding. This result is consistent with the finding of Vonk $(1984,1985)$. Her eyetracking data indicated an increase in processing time when only a single antecedent matched the morphological markings of the pronoun, suggesting that participants attempted to integrate new information with antecedent information as soon as possible. The present data go beyond Vonk's findings in suggesting an extra cost of interpretation when interpretation requires splitting a conjoined pair of proper names, compared with when a nonconjoined NP must be interpreted.

Although the present experiments indicated that the conjunction cost phenomenon could be explained without appeal to a bonding mechanism, they in no way deny the existence of such a mechanism in other circumstances. For example, Sanford and Garrod (Sanford, 1985; Sanford \& Garrod, 1989) have presented evidence that the "false antecedent" London in discourses like Driving to London was difficult. It broke down half-way. can disrupt processing. Presumably, the pronoun bonds inappropriately with London, disrupting processing when the bond must be rejected. In the materials used in the experiments reported here, it is possible that the attractiveness of proper name characters as pronoun antecedents (Garrod et al., 1993; Sanford et al., 1988) may have discouraged bonding the pronoun to the third, noun description, character.

At an empirical level, the results reported here are consistent with those reported by Garrod and Sanford (1982), aside from showing the conjunction cost they reported in a wider range of discourse structures. The present materials differed from those used by Garrod and Sanford (1982) in a few ways. Perhaps most importantly, Experiment 2 
(and the conjoined condition of Experiment 1) always included a third potential antecedent character. This was done to hold the number of protagonists in the discourse model constant across the conditions that did and did not require splitting of a conjoined phrase. It is possible that including a third individual in the discourse model foregrounded or emphasized the common discourse role(s) that the conjoined characters shared. As a result, this may have increased the likelihood that participants considered the conjoined NP as a single entity and may have increased the difficulty associated with splitting the conjoined phrase. Further, as noted in the introduction, Garrod and Sanford's (1982) pronouns always took the second conjunct as antecedent, while ours took the first. However, further research is needed to clarify this issue.

At a theoretical level, the results of the present set of experiments are consistent with Sanford and Moxey's (1995) extension of the scenario model (Sanford \& Garrod, 1981). In this model, Sanford and Moxey have addressed when it is most appropriate to refer to a conjoined pair of names with a plural pronoun and when it is most appropriate to split the conjoined pair apart and refer to one of the entities with a singular pronoun. Sanford and Moxey have suggested that the plural pronoun is most appropriate when the conjoined entities are likely to participate in the same discourse role. The demonstration of a conjunction cost in the present experiments suggests that the conjoined entities were likely to have been mapped into the same discourse role. Additional research can further test this proposal, testing it against (for example) the claim that the presence of syntactic conjunction per se, rather than a common discourse role, is the source of conjunction cost (but see Huitema, 1989, for suggestive evidence against such a claim). Such research can directly address the question that originally motivated the research reported here: the nature of the representation in which a pronoun finds its antecedent.

\section{REFERENCES}

Caramazza, A., Grober, E. H., Garvey, C., \& Yates, J. (1977). Comprehension of anaphoric pronouns. Journal of Verbal Learning \& Verbal Behavior, 16, 601-609.

Clark, H. H., \& SENGUl, C. J. (1979). In search of referents for nouns and pronouns. Memory \& Cognition, 7, 35-41.

Clifton, C., \& Ferreira, F. (1987). Discourse structure and anaphora: Some experimental results. In M. Coltheart (Ed.), Attention and performance XII (pp. 635-654). London: Erlbaum.

EHRLICH, K. (1980). Comprehension of pronouns. Quarterly Journal of Experimental Psychology, 32, 247-255.

Ehrlich, K., \& RaYNer, K. (1983). Pronoun assignment and semantic integration during reading: Eye movements and immediacy of processing. Journal of Verbal Learning \& Verbal Behavior, 22, 45-87.

Eschenbach, C. C., Habel, C., Herweg, M., \& Rehkämper, K. (1989). Remarks on plural anaphora. In Proceedings of the Fourth Conference of the European Chapter of the Association for Computational Linguistics (pp. 161-167).

GARROD, S. C. (1994). Resolving pronouns and other anaphoric devices: The case for diversity in discourse processing. In C. Clifton, L. Frazier, \& K. Rayner (Eds.), Perspectives on sentence processing (pp. 339-357). Hillsdale, NJ: Eribaum.

Garrod, S. C., Freudenthal, D., \& Boyle, E. (1993). The role of different types of anaphor in the on-line resolution of sentences in a discourse. Journal of Memory \& Language, 32, 1-30.
GarRod, S. C., \& SANFord, A. J. (1982). The mental representation of discourse in a focussed memory system: Implications for the interpretation of anaphoric noun phrases. Journal of Semantics, 1, 21-41.

GARROD, S. C., \& SANFORD, A. J. (1994). Resolving sentences in a discourse context: How discourse representation affects language understanding. In M. A. Gernsbacher (Ed.), Handbook of psycholinguistics (pp. 675-698). New York: Academic Press.

Gernsbacher, M. A., \& Hargreaves, D. (1988). Accessing sentence participants: The advantage of first mention. Journal of Memory \& Language, 27, 699-717.

Gernsbacher, M. A., Hargreaves, D. J., \& Beeman, M. (1989). Building and accessing clausal representations: The advantage of first mention versus the advantage of clause recency. Journal of Memory \& Language, 28, 735-755.

Gordon, P. C., Grosz, B. J., \& Gilliom, L. A. (1990). Pronouns, names, and the centering of attention in discourse. Cognitive Science, 17, 311-347

Huitema, J. (1989). Pronouns and the representation of discourse. Unpublished master's thesis, University of Massachusetts, Amherst.

Marslen-Wilson, W., Levy, E., \& Tyler, L. K. (1982). Producing interpretable discourse: The establishment and maintenance of reference. In R. J. Jarvella \& W. Klein (Eds.), Speech, place, and action ( pp. 339378). Chichester, U.K.: Wiley.

McKoON, G., \& RATCLIFF, R. (1980). The comprehension processes and memory structures involved in anaphoric reference. Journal of Verbal Learning \& Verbal Behavior, 19, 668-682.

O'Brien, E. J., DuFFy, S. A., \& Myers, J. L. (1986). Anaphoric inference during reading. Journal of Experimental Psychology: Learning, Memory, \& Cognition, 12, 346-352.

Rayner, K., \& Pollatsek, A. (1989). The psychology of reading. Englewood Cliffs, NJ: Prentice Hall.

RaYNer, K., \& SERENo, S. C. (1994). Eye movements in reading: Psycholinguistic studies. In M. A. Gernsbacher (Ed.), Handbook of psycholinguistics (pp. 57-77). New York: Academic Press.

Rayner, K., Sereno, S. C., Morris, R. K., Schmauder, A. R., \& Clifton, C. (1989). Eye movements and on-line language comprehension processes. Language \& Cognitive Processes, 4, SI21-49.

SANFORD, A. J. (1985). Aspects of pronoun interpretation. In G. Rickheit \& H. Strohner (Eds.), Inferences in text processing (pp. 183-205). Amsterdam: Elsevier.

SANFORD, A. J., \& GARROD, S. (1981). Understanding written language: Explorations in comprehension beyond the sentence. Chichester, U.K.: Wiley.

SANFORD, A. J., \& GARROD, S. C. (1989). What, when, and how: Questions of immediacy in anaphoric reference resolution. Language \& Cognitive Processes, 4, SI235-262.

SANFORD, A. J., \& LOCKHART, F. (1990). Description types and methods of conjoining as factors influencing plural anaphora: A continuation study of focus. Journal of Semantics, 7, 365-378.

SAnford, A. J., Moar, K., \& Garrod, S. (1988). Proper names as controllers of discourse focus. Language \& Speech, 31, 43-56

SANFORD, A. J., \& MOXEY, L. M. (1995). Notes on plural reference and the scenario-mapping principle in comprehension. In G. Rickheit \& C. Habel (Eds.), Focus and coherence in discourse processing (pp. 1834). New York: Walter de Gruyter.

VoNK, W. (1984). Eye movements during comprehension of pronouns. In A. G. Gale \& F. Johnson (Eds.), Theoretical and applied aspects of eye movement research (pp. 203-212). The Hague: Elsevier.

VoNK, W. (1985). The immediacy of inferences in the understanding of pronouns. In G. Rickheit \& H. Strohner (Eds.), Inferences in text processing (pp. 205-218). The Hague: Elsevier.

\section{NOTES}

1. To avoid confusion, individuals who were tested in the experiments are referred to as "participants" and the term "subject" is used to refer to the syntactic role.

2. The "unambiguous" and "ambiguous" antecedent labels correctly characterize the conditions in which the pronoun antecedent is a proper name. However, when the antecedent is a noun description, the name "unambiguous" is inappropriate, so we call it "unambiguous-control." There are still two potential antecedents, the noun description and one of 
the two conjoined proper names. The only difference between the ambiguous and unambiguous-control noun description conditions is the order of names in the conjoined phrase.

3. First-pass time is the summed fixation time from first entering a region to first leaving it, either to the left or to the right. Second-pass time is the summed fixation time in a region after a fixation has been made past the region, that is, the total rereading time in a region. Trials on which no fixation was made in a region were eliminated in computing first-pass time since some unknown time was presumably spent picking up information from that region when the center of fixation was outside the region. However, trials on which a region was never reread contributed a value of $0 \mathrm{msec}$ rereading time to the second-pass measure since on most trials, the region was presumably never reread. (See Rayner \& Sereno, 1994, for details and some justification of the analysis procedures used).

4. The interaction of ambiguity and region was nearly significant on first-pass time $\left[F_{1}(2,78)=2.82, M S_{\mathrm{e}}=5,756, p<.07 ; F_{2}(2,94)=3.30\right.$, $\left.M S_{\mathrm{e}}=5,618\right]$. Ambiguous sentences, both name and noun descriptions, were read relatively quickly in Region 2 and relatively slowly in Region 3 , for reasons that are unclear.

(Manuscript received January 21, 1997; revision accepted for publication October 30,1997 .) 